\title{
The Role of Urea in the Oviposition Behaviour of Japanese Encephalitis Vectors in Rice Fields of South India
}

\begin{abstract}
IP Sunish ${ }^{+}$, R Rajendran, R Reuben
Centre for Research in Medical Entomology (Indian Council of Medical Research), Chinna Chokkikulam, Madurai-625 002, India

The effect of urea on the oviposition behaviour of culicine vectors of Japanese encephalitis was studied in rice fields. Gravid females had a strong preference for oviposition in urea treated areas in rice fields, while no such preference was exhibited in untreated areas. The egg laying declined in the area where urea treated water surface had a mechanical barrier, which allowed volatile fractions to escape, but prevented contact with the water. Urea was shown to act as an oviposition attractant/stimulant for Culex tritaeniorhynchus, but its role was not clear for $\mathrm{Cx}$. vishnui, as the number of egg rafts obtained for the latter species was low.
\end{abstract}

Key words: oviposition - Culex tritaeniorhynchus - Culex vishnui - rice field - urea - India

Mosquitoes use a complex integrated sensory system for selecting an oviposition site (Vrtiska \& Pappas 1984).

Long-range cues, probably involving vision, allow mosquitoes to identify different habitats (Bidlingmayer 1975) and oviposition site characteristics. Once a potential oviposition site has been identified, short-range cues, which include temperature and chemical signals received by contact chemoreceptors, become increasingly important. Chemical cues are often the products of decay of organic matter (Mulla 1979), or may be produced by immature mosquitoes and their associated bacterial fauna (Benzon \& Apperson 1988). Gravid females of Culex vishnui and Anopheles vagus have a strong preference for ovipositing in open ground pools with little emergent vegetation as produced in the early phases of rice cultivation (Mogi \& Miyagi 1990). Cx. tritaeniorhynchus was not always adaptive in site selection, as the females were often found ovipositing on water unsuitable for larval development (Mogi 1978).

The objective of the present study was to determine the role of urea, a synthetic nitrogenous fertilizer, as an oviposition attractant/stimulant for the mosquito vectors of Japanese encephalitis (JE) virus. During a routine survey of mosquito immatures, clustering of egg rafts was observed in a localized area in a rice field at Soundarasolapuram village, Cuddalore district, Tamil Nadu State. It was later found that the farmer had selectively treated this patch with urea on the previous day, as he felt the plants were stunted. This observation prompted this exploration of the role of urea on the oviposition behaviour of vectors of JE.

This study is a part of the PhD Thesis submitted to Madurai Kamaraj University, Madurai, Tamil Nadu, India.

${ }^{+}$Corresponding author. E-mail: crmeicmr@satyam.net.in

Received 16 January 2003

Accepted 26 June 2003
A series of three experiments was conducted in rice fields 10 days after transplantation. Metal quadrats of size $0.1 \mathrm{~m}^{2}$ open at both ends were used for the experiment. One end of the quadrat was pushed into the bottom mud of the rice field, while the other end remained at least $5 \mathrm{~cm}$ above the water surface, thus preventing the mixing of water in the quadrat and the main field. The water in the quadrat was filtered to remove insect predators. In the first experiment, three paddy fields were selected and four quadrats were placed equidistant from each other at least $25 \mathrm{~m}$ apart in each of the rice fields sampled in each field. Two quadrats (T1) were treated (surface-applied) with a dose of $1 \mathrm{~g}$ urea/ $0.1 \mathrm{~m}^{2}$, while the other two were kept as untreated controls (T2). In the second experiment, the dosage of urea was increased to $2 \mathrm{~g}$ urea $/ 0.1 \mathrm{~m}^{2}$. In the third experiment, five transplanted rice fields were selected and three quadrats were placed in each field. One set of quadrat was treated with a dose of $1 \mathrm{~g}$ urea $/ 0.1 \mathrm{~m}^{2}$ (T1), the second set (T2) had a one 1 cylindrical plastic container of diameter $10 \mathrm{~cm}$ placed in it; which was filled with mud for $2 \mathrm{~cm}$ depth, and urea with similar dosage as that of $\mathrm{T} 1\left(1 \mathrm{~g} / 0.1 \mathrm{~m}^{2}\right)$ was sprinkled in the mud filled container. The container was covered with mosquito netting, to prevent the gravid females from contacting the treated water surface, but allowed the volatile fractions to escape into the atmosphere. The container was placed in the centre of the quadrat with its mouth well above the water surface, and with enough space around it so that the gravid females had access to the water surface in the quadrat. The third set of quadrats (T3) without urea application was kept as control for comparison.

In all the three experiments, the number of egg rafts was counted every morning for three consecutive days post-application. The egg rafts were brought to the laboratory, individually reared to the fourth instars or adults, identified to species and recorded. Two way ANOVA (analysis of variance) was performed using the statistical package; SPSS/PC+ version 4.0.1 (SPSS INC., Chicago, IL, US, 1984-1990), to study the effect of urea treatment on the number of egg rafts oviposited. 
In both the experiments the number of egg rafts in the urea treated quadrats was higher than the control (untreated), on all the three days of observation (Table I). Number of egg rafts was highest on the third day, being 18 and 112 in the first and second experiment respectively. Analysis of variance showed a significantly higher $\mathrm{F}$ value between the treatments $(\mathrm{F}=30.42, P=0.001)$ for the first experiment, and $\mathrm{F}=5.74, P=0.031$ for the second experiment. During the decomposition of urea, various compounds of nitrogen are formed and exist in soil and water; which are used by the rice plants. But some of the unutilized volatile fractions escape into the atmosphere, which could be responsible for attracting the gravid females for oviposition. In rice fields of South India, it was observed that fertilizer application was followed by a rise in concentration of nitrogen compounds in the water and a subsequent increase in larval density (Sunish et al. 1998, Sunish \& Reuben 2001). Ikemoto and Sakaki (1979) observed a high degree of positive correlation between the number of Anopheles sinensis immatures and ammonianitrogen concentrations in the rice field water. They concluded that amount of ammonia-nitrogen in the water greatly influences the oviposition of these mosquitoes. It was reported earlier (Ferguson et al. 1984, Rachhpal-Singh 1987) that surface-applied urea easily gets converted to unstable form, which quickly change to ammonia and carbon dioxide. Under less ideal conditions, the ammonia is lost to the atmosphere by volatilization. Victor and Reuben (2000) also observed an increased abundance of $C x$. vishnui subgroup larvae in rice fields after the application of inorganic fertilizer. In the third experiment of the present study, the number of egg rafts in the various treatments differed significantly from each other $(P=$ 0.027) (Table II). Fewer egg rafts were found in the quadrat where the urea treated container with mosquito netting was present. By Duncan multiple range test (DMRT), it was observed that the number of egg rafts in this quadrat was significantly different from those found in the urea treated quadrat; while no difference was observed to the untreated area. It can be speculated that, egg laying might have been reduced in this quadrat because the females were prevented from physically contacting the treated water surface (T2) even though the gravid females have been attracted to the urea treated site. This may have been

TABLE I

Number of egg rafts collected from quadrats with and without urea application in transplanted rice fields

\begin{tabular}{cccccc}
\hline & \multicolumn{2}{c}{ Experiment $1{ }^{a}$} & & \multicolumn{2}{c}{ Experiment ${ }^{b}$} \\
\cline { 2 - 3 } \cline { 5 - 6 } $\begin{array}{l}\text { Days after urea } \\
\text { application }\end{array}$ & $\begin{array}{c}\text { Quadrats with urea application } \\
\left(1 \mathrm{~g} / 0.1 \mathrm{~m}^{2}\right) \mathrm{T} 1\end{array}$ & $\begin{array}{c}\text { Quadrats without } \\
\text { urea } \mathrm{T} 2\end{array}$ & & $\begin{array}{c}\text { Quadrats with urea application } \\
\left(2 \mathrm{~g} / 0.1 \mathrm{~m}^{2}\right) \mathrm{T} 1\end{array}$ & $\begin{array}{c}\text { Quadrats without } \\
\text { urea }\end{array}$ \\
\hline 1 & 6 & 0 & 10 & 0 \\
2 & 15 & 0 & 2 & 0 \\
3 & 18 & 0 & 112 & 10 \\
\hline
\end{tabular}

$a: P=0.001 ; b: P=0.031$

TABLE II

Number of egg rafts collected from urea applied quadrats (T1), quadrats with urea treated container with netting (T2) and quadrats without urea applied (T3)

\begin{tabular}{cccc}
\hline $\begin{array}{l}\text { Days after urea } \\
\text { application }\end{array}$ & $\begin{array}{c}\text { Treated with urea } \\
\text { at } 1 \mathrm{~g} / 0.1 \mathrm{sqm} \mathrm{T1}\end{array}$ & $\begin{array}{c}\text { Quadrat with container treated } \\
\text { with urea at } 1 \mathrm{~g} / 0.1 \mathrm{~m}^{2} \mathrm{~T} 2\end{array}$ & $\begin{array}{c}\text { Quadrats } \\
\text { without urea }\end{array}$ \\
\hline 1 & 21 & 5 & 7 \\
2 & 12 & 5 & 7 \\
3 & 5 & 0 & 1 \\
\hline
\end{tabular}

\section{ANOVA Table}

\begin{tabular}{lrrrr}
\hline Source & df & S S & MS & F \\
\hline Treatments & 2 & 36.13 & 18.07 & $4.077^{a}$ \\
Replicates & 4 & 17.47 & 4.47 & 0.98 \\
Interaction & 8 & 39.87 & 4.98 & 1.12 \\
Error & 30 & 133.33 & 4.44 &
\end{tabular}

$a: P=0.027$

DMRT analysis

\begin{tabular}{lcccc}
\hline & $\begin{array}{c}\text { T1 (treated with } \\
\text { urea at } 1 \mathrm{~g} / 0 . \mathrm{m}^{2} \text { ) }\end{array}$ & $\begin{array}{c}\text { T2 (quadrat with container } \\
\text { treated with urea at } 1 \mathrm{~g} / 0.1 \mathrm{~m}^{2} \text { ) }\end{array}$ & $\begin{array}{c}\text { T3 } \\
\text { (untreated) }\end{array}$ & CD value \\
\hline Egg rafts (Mean number) & $12.67^{a}$ & $3.33^{b}$ & $3.00^{b}$ & 1,57 \\
\hline
\end{tabular}

Values followed by the same letter do not differ significantly from each other. 
because the volatile substances, which could escape through the netting, were acting as attractants but not as stimulants for oviposition. Bentley et al. (1981) demonstrated that several compounds involved in oviposition site selection and oviposition by Aedes triseriatus only exerted their effects when perceived by contact receptors, even though the compounds were volatile enough to be perceived by olfaction. Beehler et al. (1993) have also shown experimentally that gravid $C x$. quinquefasciatus have to touch the water surface with the tarsi to detect the presence of micro-organisms or by products from micro-organisms, for stimulating oviposition. Hence, preventing the gravid females from contacting the treated water surface due to netting has resulted in reduced egg laying.

Out of 236 egg rafts identified, the majority were of Cx. tritaeniorhynchus Giles (78\%), followed by $C x$. vishnui Theobald (18\%). Other culicines identified were Cx. pseudovishnui Colless, Cx. fuscocephala Theobald and $C x$. bitaeniorhynchus Giles. Urea fertilizer was found to act as an oviposition stimulant for $C x$. tritaeniorhynchus, as $91.4 \%$ of egg rafts of this species were collected from urea treated quadrats than untreated quadrats. The role was not clear for $C x$. vishnui as the number of egg rafts obtained were low with 26 and 16 numbers from the urea treated and untreated quadrats respectively.

Mosquitoes may get attracted towards an oviposition site, but relatively few of them may actually oviposit. Further studies are needed to determine the role of various volatile fractions of urea and other nitrogenous fertilizers, which are used in the rice ecosystem in the oviposition behaviour of the mosquito vectors. In natural situations, chemical compounds do not act independently in attracting or stimulating gravid female mosquitoes. They interact with other biotic and abiotic factors at the oviposition site, and together they present an integrated picture of the quality and attractiveness of the oviposition site (Beehler et al. 1993).

\section{ACKNOWLEDGEMENTS}

To Dr K Satyanarayana, Officer on Special Duty/Director, and Dr A Gajanana, former Officer in Charge, CRME (ICMR), Madurai for providing excellent facilities to complete this study. To Dr P Philip Samuel, Research Scientist, CRME for his valuable help during the study period. To Shri M Muthusamy Naidu, Agriculturist, Soundarasolapuram, Cuddalore District, Tamil Nadu State, India, for permitting us to carry out the study in his fields. To Shri K Venkatasubramani, Shri T Kannan and other field staff of CRME, Vridhachalam, for technical assistance.

\section{REFERENCES}

Beehler JW, Millar JG, Mulla MS 1993. Synergism between chemical attractants and visual cues influencing oviposition of the mosquito Culex quinquefasciatus (Diptera: Culicidae). J Chem Ecol 19: 635-644.

Bentley MD, McDaniel IN, Yatagai M, Lee HP, Maynard R 1981. Oviposition attractants and stimulants of Aedes triseriatus (Say) (Diptera: Culicidae). Environ Entomol 10: 186-189.

Benzon GL, Apperson CS 1988. Re-examination of chemically mediated oviposition behaviour in Aedes aegypti (L.) (Diptera: Culicidae). J Med Entomol 25: 158-164.

Bidlingmayer WL 1975. Mosquito flight paths in relation to the environment. Effect of vertical and horizontal visual barriers. Ann Entomol Soc Am 68: 51-57.

Ferguson RB, Kissel DE, Koelliker JK, Wes Basel 1984. Ammonia volatilization from surface-applied urea: effect of hydrogen ion buffering capacity. Soil Sci Soc Am J 48: 578-582.

Ikemoto T, Sakaki I 1979. Physico-chemical characters of the water in rice fields in relation to their suitability of the mosquito larvae, Anopheles sinensis. Jap J San Zool 30: 87-92.

Mogi M 1978. Population studies on mosquitoes in the rice field area of Nagasaki, Japan, especially on Culex tritaeniorhynchus. Trop Med 20: 173-263.

Mogi M, Miyagi I 1990. Colonization of rice fields by mosquitoes (Diptera: Culicidae) and larvivorous predators in a synchronous rice cultivation areas in the Philippines. J Med Entomol 27: 530-536.

Mulla MS 1979. Chemical ecology of mosquitoes auto and transpecific regulating chemicals in nature. Proc Pap Calif Mosq Cont Assoc 47: 65-68.

Rachhpal-Singh J 1987. Predicting the effect of soil-water-air dynamics on ammonia volatilization from applied urea with a mechanistic model Fertlizer Research 13:277-285.

Sunish IP, Reuben R 2001. Factors influencing the abundance of Japanese encephalitis vectors in rice fields in India Abiotic. Med Vet Entomol 15: 381-392.

Sunish IP, Raghunatha Rao D, Gajanana A 1998. Nitrogenous fertilizers, neem and vectors of Japanese encephalitis virus. Curr Sci 75: 1107.

Victor TJ, Reuben R 2000. Effects of organic and inorganic fertilizers on mosquito populations in rice fields of Southern India. Med Vet Entomol 14: 1-8

Vrtiska LA, Pappas LG 1984. Chemical analysis of mosquito larval habitats in Southeastern Nebraska. Mosq News 44: 506-509. 